\title{
CELLULOSE-BASED HYDROGELS IN TISSUE ENGINEERING APPLICATIONS
}

\author{
DANIELA RUSU, ${ }^{*}$ DIANA CIOLACU* ${ }^{*}$ and BOGDAN C. SIMIONESCU ${ }^{* * * *}$ \\ * "Petru Poni” Institute of Macromolecular Chemistry, \\ Romanian Academy, Iasi, Romania \\ ** Department of Natural and Synthetic Polymers, "Gheorghe Asachi” Technical \\ University of Iasi, Iasi, Romania \\ \Corresponding author: Diana Ciolacu, dciolacu@icmpp.ro
}

Dedicated to the $70^{\text {th }}$ anniversary of the Department of Pulp and Paper, "Cristofor Simionescu" Faculty of Chemical Engineering and Environmental Protection,

"Gheorghe Asachi" Technical University of Iasi

In the last decade, the field of medicine is at the epicentre of recent technological growth and innovation, while major changes have occurred in areas such as tissue engineering, in terms of concepts, knowledge and materials. In this regard, hydrogels are one of the materials of the future, due to their outstanding adaptability, which makes their applications almost endless. These are three-dimensional polymeric networks able to display biomimetic properties, a characteristic that is considered optimal to deliver bioactive principles and engineer injured tissues. Due to their high water content and compatibility with cells, hydrogels may infiltrate into specific or non-specific binding with cell receptors.

In addition, with increased concerns about environmental impacts and the emergent request for new eco-friendly materials, researchers are focusing particularly on the application of natural polymer-based hydrogels in the biomedical engineering field, in order to reach non-toxicity, abundance of starting materials, novel features and biomimetic properties. Cellulose and cellulose derivatives represent a class of biopolymers that exhibit the particular capability to participate in different biomedical applications due to their excellent biocompatibility and biodegradability, tunable properties and low cost.

This review focuses on the key aspects and recent advances regarding the design, properties and applications of hydrogels based on cellulose and its derivatives, in the broad area of tissue engineering.

Keywords: cellulose, hydrogels, biomaterials, tissue engineering, regenerative medicine

\section{INTRODUCTION}

Tissue engineering is an important domain in regenerative medicine, with rapidly expanding research directed to the preparation of new biomaterial matrices with adjusted properties to generate functional tissues for specific applications.

Most efforts in the field focus on the most suitable pathways to preserve, restore or enhance tissue functions and also to replace diseased and damaged organs or tissues. Designing a biocompatible scaffold with optimal characteristics related to the above is the main key element for successful tissue engineering. ${ }^{1}$

Hydrogels have evolved as prime candidates for engineered tissue matrices due to their distinctive structural and compositional similarities to natural tissues, in addition to their advantageous architecture for cellular multiplication and survival. Moreover, the possibility to control the shape, size, porosity and morphological aspects of hydrogel matrices has created new occasions to overcome multiple challenges in the tissue engineering field, such as concomitant seeding of multiple cells, vascularization and tissue architecture. ${ }^{2}$

Among the most promising polymeric materials, hydrogels are a special class, which has attracted wide interest in the last decades, being the first biomaterial designed for use in the human body. Since these remarkable materials were first reported at the end of the 60 s by Witchterle and 
Lim, ${ }^{3}$ different preparations, allowing a myriad of structures, properties and applications, have been described in a vast number of articles.

Hydrogels are exceptional polymeric materials that maintain a distinct three-dimensional (3D) architecture. The high-water holding capacity offers them the advantage of biocompatibility with living tissues and physicochemical similarity to the extracellular matrix (ECM). This outstanding class of 3D polymeric materials found applications in a wide palette of domains, such as tissue engineering, drug delivery systems, regeneration and cell transplantation. Moreover, these types of formulations can be used in a noninvasive manner, taking into account their favourable properties regarding tissuebiocompatibility, high water content and facile control of solute transport. ${ }^{4}$

Nowadays, hydrogels can be composed in diverse forms, starting from various polymers, by using advanced techniques, which makes them extremely versatile, biodegradable and safe. ${ }^{5}$

The characteristics of hydrogels derive from the preparation method - these outstanding materials can be obtained either by physical or by chemical cross-linking processes. The networks of the physically cross-linked formulations are aggregated by molecular entangling, ionic and hydrogen bonding or hydrophobic interaction forces to form a reversible structure. On the other hand, the chemical cross-linking process is a permanent junction formed by covalent bonds, with a relatively strong and stable connection between diverse functional groups introduced by using different cross-linking agents. ${ }^{6,7}$

Over the past few decades, polymeric materials have greatly influenced the development of new technologies, the expansion of science borders and the advancement of modern medicine, due to the fact that polymers are easily processed and chemically modified to match the requirements of specific biomedical applications. Different polymers of natural and synthetic origin or natural-synthetic hybrid polymers featuring different architectures and consequently, desired chemical, physical and mechanical properties, are used in different fields, such as medicine, ${ }^{8}$ engineering, ${ }^{9,10}$ agriculture. ${ }^{11,12}$

The original sources of hydrogels are usually divided into natural and synthetic polymers. Naturally sourced hydrogels, often called biopolymer-based hydrogels, have explicit biomedical applications and superior properties as compared to their synthetic counterparts in terms of biocompatibility, biodegradability, non-toxicity and biomimetic features. At the same time, the use of natural hydrogels can overcome some difficulties like cell growth and differentiation and long-term safety of implants. ${ }^{13}$ These characteristics are also able to overcome some drawbacks of the synthetic-based analogues, like chronic inflammation or immunological response and toxicity. ${ }^{14}$

Natural polymers used in hydrogels include (i) proteins, such as collagen, gelatin, silk fibroin, elastin, fibrinogen, keratin, etc. and (ii) polysaccharides, such as chitosan, alginate, cellulose, dextran, xanthan, gellan gum, etc. Polysaccharide-based hydrogels have become particularly interesting as scaffolds for the repair and regeneration of a wide variety of tissues and organs, since this class of natural polymers can function as effective extracellular matrices to direct cellular behaviour.

Cellulose represents the most abundant naturally occurring biopolymer, biodegradable by nature. Cellulose-based hydrogel materials are preferred in biomedical and pharmaceutical applications due to their advantages regarding biocompatibility, high mechanical and thermal stability, non-toxicity and also cost-efficiency. Thanks to all of these premises, they are often used in the biomedical field, in applications such as blood purification membranes in artificial kidneys, body water retainers, artificial cartilage, ocular bandages, scaffolds for regenerative medicine and stomach bulking agents. ${ }^{15}$

This review describes the most recent and relevant strategies for achieving cellulose-based hydrogels with special emphasis on designing, properties and applications in the tissue engineering field.

\section{TISSUE ENGINEERING \\ General aspects}

Tissue engineering is a rapidly advancing interdisciplinary field involving biomaterials science, cell biology, cell-material interactions and fitting biochemical and physicochemical factors to upgrade or replace biological tissues. Research in this area aims to restore, maintain, or enhance tissue functions that are inoperative or have been lost as a result of accidents or disease by different clinical circumstances, either by evolving biological substitutes or by recreating tissues. ${ }^{16}$

Irrespective of the tissue or organ to be engineered, the basic concept for the tissue 
engineering technology involves cell sourcing, isolation and proliferation, fabrication of biodegradable scaffolds or polymers, seeding of cells on scaffolds to create constructs and the application of in vitro or in vivo bioreactor options (Fig. 1). ${ }^{17}$

The two main constituents of the tissues in the human body are cells and extracellular matrix (ECM). Cells regulate body processes performing normal maintenance and wound healing, meanwhile ECM components, composed of a dynamic arrangement of polysaccharides and proteins (collagen, elastin, fibrinogen, silk fibroin, elastin, keratin, etc.), serve as the major structural component of the body. In tissue engineering applications, the cell-ECM interactions play an important role in day-to-day cellular activity and wound healing process. ${ }^{18}$

Tissue engineering requires the use of cells, engineered extracellular matrices ("scaffolds") and biological molecules in order to create a novel set of tissue substitution pieces and implementation approaches for a medical cause.

The field of tissue engineering experienced an exponential growth in recent years, fuelled by technological advancements in medicine, biology, materials science, especially when it comes to proliferation and differentiation ingredients and biomimetic environments.
The development of the tissue engineering domain is linked to the advancement of basic research in tissue and matrix growth factors, developmental biology, materials science and also bio-informatics.

Scaffold design and production are important topics for regenerative medicine and tissue engineering since any involved material has to mimic the extracellular matrix of the native tissue and its success is a key factor for the overall application. Natural polymer-based structures are capable of bearing three-dimensional tissue formation and usually serve for one of the mentioned purposes: deliver and hold cells and biochemical factors, allow spreading of vital cell nutrients, allow cell attachment, growth and proliferation.

Scaffolds must reach a number of specific requirements so as to be used in tissue reconstruction - $\quad$ biocompatibility, biodegradability and high porosity to smooth the way for cell seeding and diffusion all through the entire structure of cells and nutrients. Biodegradability is an essential demand since matrices should ideally be absorbed by the nearby tissues without the need of surgical displacement; as a consequence, the rate at which degradation takes place has to occur simultaneously with the rate of tissue evolution. ${ }^{19}$

\section{The Basic Tissue Engineering Paradigm}

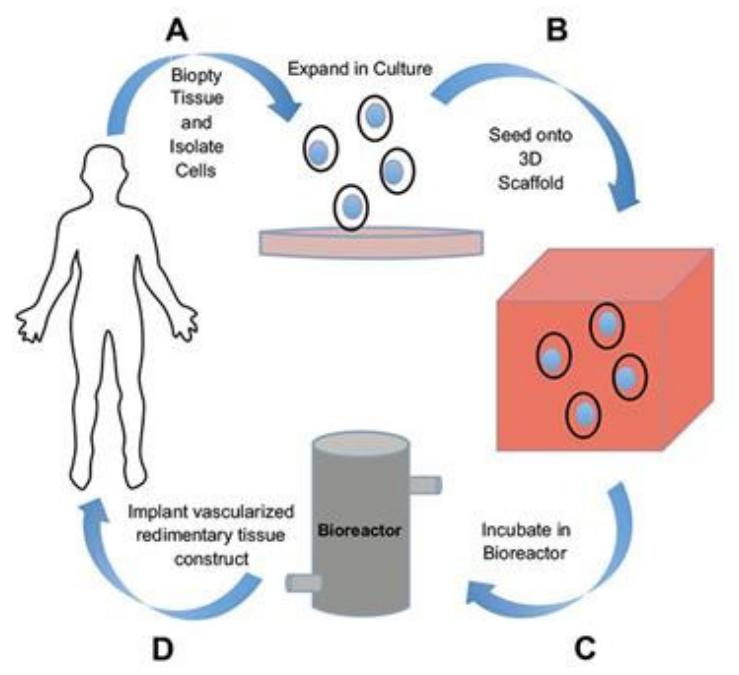

Figure 1: Basic principles of tissue engineering (reprinted with permission from R. Kumar et al., ${ }^{17}$ Copyright $@ 2016$, Bentham Science Publishers) 
Researchers have developed several techniques to shape natural polymers into complex frameworks that exhibit the desired demands for the production of medical devices and tissue-engineering scaffolds. Polymeric scaffolds are leading players in the field since they offer distinct properties, such as biocompatibility, high surface-to-volume ratio, interconnected surface porosity, biodegradability and mechanical strength, which represent crucial features in tissue engineering and organ replacement. ${ }^{20}$ Therefore, various concepts and pathways have been employed in recent years to construct biologically active scaffolds based on natural or synthetic polymers so as to restore functions or regenerate tissues. Such scaffolds behave as a temporary matrix for cell growth and differentiation, with subsequent ingrowth up to the point when tissues are totally replaced or regenerated.

Natural polymers can be considered the first clinically used biodegradable scaffold materials due to their bioactive properties and lack of an immune response. ${ }^{21}$ As compared to their synthetic homologues, these biodegradable materials have superior interactions with the cells, thus enhancing their performance in biological systems. The use of natural polymers to create tissue engineering scaffolds has yielded promising results, in vitro as well as in vivo studies, either by inducing surrounding tissue and cell ingrowth or by serving as temporary scaffolds for transplanted cells to attach, grow and maintain differentiated functions. ${ }^{22}$

\section{Hydrogel scaffolds for tissue engineering applications}

In the last decades, a significant body of research has focused on the utilization of hydrogels as scaffolds for tissue engineering, due to their network structure, which provides appropriate microenvironments for cellular attachment, proliferation, and migration, as well as to the unique compositional and structural similarities with ECM. Furthermore, the design and applications of natural-based hydrogels has increased the impact of hydrogel scaffolds in the biomedical field and enabled major advances in tissue engineering.

Hydrogel-based scaffolds used in tissue engineering have to fulfil a set of design criteria and to ensure the possibility to tailor their mechanical and physicochemical parameters, in order to mimic those of natural tissues. A basic design criterion required for a scaffold used in tissue engineering is to maintain the proliferation and migration of cells during the life of the scaffold. Regarding this aspect, the rate and extent of biodegradation are critical parameters for hydrogels in tissue engineering since in many cases the scaffolds' life depends on the level of degradation. $^{23}$ In order to optimize tissue regeneration, the degradation behaviour of all biodegradable 3D hydrogel frameworks should match the rate of certain cellular processes and should therefore provide reproducible, welldefined and tunable architecture. ${ }^{24,25}$

Biopolymer-based hydrogels are frequently used in tissue engineering applications (like bone tissue, cartilage tissue, vascular tissue, meniscus, tendon, skin, cornea, and soft tissues) since they bring particular advantages, such as cell-guided degradability and inherent cellular interaction. Also, their biocompatibility is a very important feature, taking into account that tissue scaffolds continuously interact with the body during scaffold degradation and cellular regeneration. Therefore, hydrogel matrices developed for tissue engineering should be safe, non-toxic, with no or very limited immunological response, otherwise the engineered constructs may be harmful for the connected tissues or can be non-functional. ${ }^{26}$

In terms of morphology, hydrogel scaffolds for tissue engineering purposes must be highly porous to permit uniform cell distribution and encourage cell ingrowth. Parameters such as pore interconnectivity, pore shape and pore size distribution are significant when designing a hydrogel matrix, to control the cellular penetration and extracellular matrix production. The effects of scaffold optimum pore sizes and pore interconnectivity have been reported in many studies related to tissue engineering. ${ }^{27}$

\section{CELLULOSE-BASED HYDROGELS FOR TISSUE ENGINEERING}

Nowadays, the wide range of strategies employed to engineer tissues depend on the use of a proper scaffold material, which plays the role of a synthetic extracellular matrix (ECM) and ensures the desired properties in direct correlation with a specific application. ${ }^{28-30}$

Naturally derived hydrogels containing cellulose are used as porous skeletons to imitate the roles of extracellular matrices and to engineer different in situ or in vitro tissue types, including cartilage, muscle, bone, skin, fat, liver, ligament, tendon and neurons, by providing the supporting 
space and nutrients for the formation of new biological constructs and the overall control of its structure and function. ${ }^{31,32}$ Moreover, they ensure the mechanical support for long-term cellular growth and distribution, in combination with the biodegradability necessary to faster the proliferation of the replacement tissue. ${ }^{33,34}$

Cellulose is the most abundant, naturally occurring macromolecule, with a myriad of sources, from natural fibres from plants to microfibrils from bacteria. ${ }^{35,36}$ The chemical structure of cellulose is the same regardless of its origin: anhydroglucose units (AGUs) connected by $\beta-1,4$-glycosidic bonds between the $\mathrm{C} 1$ and $\mathrm{C} 4$ positions. ${ }^{37}$

This eco-friendly resource combines some outstanding features, such as biocompatibility, biodegradability, non-toxicity, mechanical and thermal stability, hydrophilicity and costefficiency, with the possibility to adjust its characteristics and obtain derivatives with tunable functionalities by relatively simple chemical modification procedures. ${ }^{38,39}$

Cellulose-based hydrogels represent a hot research topic in material science. They combine all the positive characteristics of cellulose within a tailorable porous architecture and thus hold a great potential for a wide palette of applications, from smart materials and agriculture to drug delivery and pharmaceutical formulations. ${ }^{40,41}$ These scaffolds are appropriate materials to address different directions in the field of tissue engineering, finding use as biocompatible, hydrophilic, low cost 3D structures that provide structural integrity to tissue constructs, organize cells and direct the growth and formation of a desired biological framework. ${ }^{42-46}$

The key feature of cellulose-based hydrogels comes from their highly swollen threedimensional (3D) architecture, which resembles soft tissues and allows the diffusion of bioactive molecules through the porous network. The obtained scaffolds possess a top position in both cell targeting and cell transplantation strategies. They ensure biocompatible three-dimensional surfaces that promote the attachment, proliferation and migration of cells and connective tissue progenitors. Moreover, scaffold matrices are employed as delivery vehicles for bioactive molecules to a particular graft site, making easier the retention and diffusion of cells throughout the area where new tissue is needed. ${ }_{50}^{47-}$
Different methods have been used for the production and processing of porous matrices based on cellulosic materials. ${ }^{51}$ The abundance of natural sources is maintained in the case of cellulose based hydrogels, which can be obtained either directly from native cellulose (bacterial, plant sources) or from cellulose derivatives, such as methylcellulose (MC), carboxymethyl cellulose (CMC), hydroxypropyl methylcellulose (HPMC), dialdehyde cellulose (DAC), cellulose acetate (CA), etc. ${ }^{51}$ All these cellulosic materials preserve the bio-related characteristics and the quality to be used as trustworthy scaffolds in the biomedical field to treat, augment or replace certain tissues. ${ }^{52-}$ 54

The starting raw materials are widely available, since this is the most abundant biopolymer worldwide: plants, for which it ensures structural and mechanical integrity ${ }^{55,56}$ and certain types of bacteria, which are able to produce the so-called bacterial cellulose starting from glucose or similar carbon sources. ${ }^{57-59}$ The latter is preferred as starting material for hydrogels since it provides longer macromolecular chains, higher purity and superior tensile strength as compared to its analogue.

The key features of bacterial cellulose (BC) come from its microfibrillar nanostructure, which enables a high degree of crystallinity, large surface area, low density, proper mechanical characteristics and improved hydrophilicity, all of which make $\mathrm{BC}$ an attractive choice for tissue engineering applications. ${ }^{60-62} \mathrm{BC}$ obtained from cultures of the Gram-negative Gluconacetobacter xylinus bacteria produces highly hydrated membranes of certain undeniable potential in tissue engineering, as it can be easily manipulated to enhance its functionalities and properties through resulting $\mathrm{BC}$ composites. $\mathrm{BC}$ membranes bring additional features in tissue engineering, like non-immunogenic answer and the capability of supporting cell differentiation, ${ }^{63,64}$ and the association with other materials may further upgrade their biological and mechanical properties. ${ }^{65-67}$

Cellulose derivatives, such as $\mathrm{MC}, \mathrm{CMC}$ and HPMC, have been extensively used over the years to manufacture cellulose-based hydrogels through physical and chemical cross-linking reactions due to their excellent biocompatibility, biodegradability and environmental friendliness. ${ }^{68}$ They are extensively used in the regeneration of 
different tissues, such as bone, heart, cartilage, blood vessel and nerve, among others.

The methyl derivative of cellulose, $\mathrm{MC}$, has the specific property of forming thermo-reversible hydrogels on heating, and is classified as a lower critical solution temperature (LCST) polymer. $\mathrm{MC}$ is a biocompatible material that exhibits good cell adhesion, being systematically investigated as a component of hydrogel scaffolds for the cell sheet engineering field. ${ }^{69-71}$

The other cellulose derivatives provide several grades of hydrophilicity, processability, mechanical and rheological behaviour. Moreover, a myriad of formulations are obtained by combining these derivatives with various polymers to create cellulose-polymer composites with particular characteristics. This cost-efficient and manifold advantageous method is used on a large scale to obtain novel materials for tissue engineering applications. ${ }^{72}$

\section{Cell regeneration}

In the past decade, cell sheet engineering has evolved as a different viewpoint for tissue engineering. The use of extracellular scaffolds in order to regenerate different tissues possesses the advantage of removing the manipulation of biodegradable scaffolds to maintain the growth and evolution of cells into tissues. ${ }^{73-78}$ They supply structural integrity to tissue constructs and serve as barriers between the tissue and an external material.

Many examples in which cellulose derivatives are used to establish 3D cell cultures are available in the recent literature.

The thermo-responsive behaviour of MC has been systematically investigated in the last years in order to evaluate its potential in designing and obtaining MC-based hydrogel systems for cell sheet engineering applications. In some cases, thermo-sensitive hydrogels are used as a coating of culture dishes for harvesting living cell sheets. In this respect, a relatively simple thermoreversible hydrogel system was fabricated by blending aqueous $\mathrm{MC}$ solutions with distinct salts on tissue culture polystyrene (TCPS) dishes at 20 ${ }^{\circ} \mathrm{C}$. Only the aqueous MC compositions that form a gel at $37{ }^{\circ} \mathrm{C}$ were chosen for the study. The hydrogel formulation composed of $8 \% \mathrm{MC}$ in phosphate buffer (PBS) stayed intact throughout the entire process of cell culture, an important feature for cell sheet engineering.

In the above described procedure, it is difficult to obtain a stable and viable hydrogel system because of the high viscosity of the MC formulations. In order to improve cell attachment, the MC/PBS hydrogels are modified by incorporating collagen into the matrix. A sustained monolayer cell sheet has been obtained on the surface of the MC/PBS/collagen ensemble, which showed better activity as compared to the uncoated TCPS dish, according to MTT assays. The developed hydrogel system can be used for tissue reconstruction and also for culturing multilayered cell sheets. ${ }^{79}$

Novel thermo-responsive MC-collagen hydrogel systems were designed for the construction of multi-dimensional cell sheets and specifically adjusted to function for adipose tissue derived stromal-stem cells (ASCs). Three commercially accessible MCs were investigated by swelling and degradation measurements in cell culture solutions, which showed $32{ }^{\circ} \mathrm{C}$ to be the optimal hydrogel incubation temperature.

The systems were evaluated as composite supports that promote the adhesion and proliferation of ACS cultures at different time intervals. A MC-type I (bovine) collagen combination $\left(\mathrm{pH}=7.5 ; 37^{\circ} \mathrm{C}\right)$ proved to upgrade the adhesion and proliferation of ASC cells to continuous monolayer sheets, which, after incubation and exposure to room temperature, voluntarily and gradually detach from the composite surface. ${ }^{80}$

This method empowers the preparation of single- and multi-layered cell constructs, while preserving cell-cell and cell-extracellular matrices interplays.

Tang et al. prepared an injectable threedimensional matrix for tissue engineering by combining two thermo-sensitive hydrogels, MC and chitosan, with different salt gels at $37^{\circ} \mathrm{C}$. 3D architectures ranging from nonporous to microporous were obtained and they proved to be appropriate scaffolds for chondrocyte attachment, growth and proliferation. ${ }^{81}$

\section{Bone tissue engineering}

One of the major challenges facing bone tissue engineering is the development of porous scaffolds with good mechanical properties that retain proper vascularization and provide a robust structural support with fast response to metabolic demand. $^{82,83}$

These types of scaffolds also require bioactivity, controllable biodegradability, 3D porous architecture and the capacity to stimulate osteodifferentiation and angiogenesis. ${ }^{84-86}$ 
Since they possess the innate ability to satisfy a big part of this checklist, hydrogels based on natural polymers have been extensively employed in bone and cartilage tissue engineering. ${ }^{87-89}$

Fricaina et al. studied the employment of regenerated cellulose hydrogels in the treatment of femoral trauma. Although biocompatible, the hydrogels did not prove suitable for osseointegration. Phosphorylation was used in order to enhance cellulose bioactivity. In vitro studies showed that regenerated cellulose hydrogels led to bone cells attachment and growth, but no cellular mineralization was noticed. On the other hand, in the physiological state, phosphorylated cellulose hydrogels generated the development of a calcium phosphate layer, which behaved as a poor matrix for bone cell attachment. The bone regeneration process was investigated 6 months postimplantation of unchanged and phosphorylated cellulose hydrogels in rabbits, and based on histological observations, histomorphometry measurement and the quantity of $45 \mathrm{Ca}$ incorporated in the nearby tissue, it was concluded that phosphorus-modified cellulose hydrogels exhibit better osteointegration than the unmodified ones. ${ }^{90}$

Another study has used regenerated cellulose and hydroxyapatite (HA) coated cellulose hydrogels in the search for an optimal bone substitute. The biomaterials were implanted into femoral bone defects of rats for 52 weeks, and biochemical and histological assays showed that the HA-coated hydrogels did not promote bone formation and favoured an inflammatory reaction of higher intensity, as compared to the uncoated cellulose hydrogels. ${ }^{91}$

Sukul et al. developed a new hydrogel scaffold based on gelatin, nanofibrillar cellulose and $\beta$ tricalcium phosphate (TCP), displaying both osteoconductive and osteoinductive characteristics. Nanofibrillar cellulose reduced the degradation rate of the hydrogel matrix, which in turn favoured the gradual and constant release of the simvastatin entrapped in the scaffold. MicroCT and histological analysis concluded that the hydrogel construction containing a certain amount of simvastatin supports cell growth and differentiation under in vitro conditions and observed a greater extent of bone evolution in critical-sized rat calvarial imperfections at two different points in time: 4 and 8 weeks, respectively. These data suggest that the gelatinnanofibrillar cellulose- $\beta$ tricalcium phosphate
(TCP) scaffold, containing simvastatin, generates an osteoconductive architecture and enhances the osteogenesis of the bone. ${ }^{92}$

Injectable hydrogels are another suitable class of biomaterials for resolving complex-shaped bone defects. Different studies underline that silated hydroxypropylmethyl cellulose (SiHPMC) provides intergranular spaces for bone ingrowth, while calcium phosphate particles reinforce the bone healing process by osteoconduction. Thus, the obtained macrostructures possess multiple favourable features for bone ingrowth due to the proper porous architecture, which ensures interconnectivity, permeability and boosts bone regeneration. ${ }^{93-86}$

Fellah et al. developed an injectable and selfcrosslinkable bone substitute (IBS2) based on a Si-HPMC hydrogel, which is mechanically stable, and biphasic calcium phosphate (BCP) ceramics. This system was investigated in the treatment of critical-sized femoral defects. The observations after injection revealed that the IBS2 completely filled the bone defects and Si-HPMC behaved as a carrier for the BCP particles, creating in the same time intergranular spaces for bone ingrowth. The Si-HPMC framework immobilized the BCP particles, while the latter provided the demanded bioactivity to support the bone healing process by osteoconduction. At the end, no signs of inflammation were observed and the osteointegration of BCP particles in IBS2 behaved as a dynamic process, which evolves together with the healing of bone tissue. After 8 weeks of implantation in rabbits with femoral defects, the newly formed bone was found to be significantly stronger than the surrounding trabecular bone. This new injectable hydrogel qualifies therefore for the reconstruction of critical size bone defects, using minimally invasive approaches. ${ }^{97}$

Various biomaterials are investigated in combination with conventional scaffolds in the treatment of human periodontal defects, to obtain both the bone filling of the envisaged defects and a complete regeneration of all periodontium components. $^{98}$ Injectable polymers were developed in order to be used in this regard, in combination with bone graft materials, but the mechanical properties of Si-HPMC after reticulation still need to be optimized in order to improve the viscosity and hardness, so as to obtain a material that responds to the specificities of this medical problem. ${ }^{99}$ 
Struillou et al. assessed an injectable hydrogel composed of Si-HPMC and BCP ceramic particles for treating periodontal osseous defects in dog models. This composite hydrogel functions as a potential scaffold for bone regeneration, simplifying the process of filling periodontal lesions: Si-HPMC exhibits convenient rheological properties and gives consistency to the material by linking $\mathrm{BCP}$ particles together in order to improve their stability in bone defects. The hydrogel has the proper viscoelastic properties to ensure retention of BCP in bone defects during healing and promotes new bone formation at 3 months post-implantation in dogs. ${ }^{100}$ This injectable composite hydrogel has also been tested for use in dental surgery to resolve alveolar ridge resorption prior to dental implantation. ${ }^{101,102}$

The same research team modified the viscosity of this system by increasing the concentration of the hydrogel from 3 to $4 \%$ as to immobilize BCP particles in the periodontal, critical-sized defects during the surgical phase. After a 12 weeks implantation period, the Si-HPMC hydrogel was acting as a valuable occlusive membrane, which protected the bone area from soft connective tissue invasion and contributed to upgrading bone regeneration. Future preclinical investigations are needed to confirm the success of this system in periodontal regeneration. ${ }^{103}$

By using two natural polymers - $\mathrm{BC}$ and gelatin, Nakayama et al. obtained biocompatible hydrogels with good mechanical properties and a low frictional coefficient, comparable to that of articular cartilage. ${ }^{104}$

Other 3D BC membranes based on cellulose nanofiber networks display improved mechanical properties, as compared to other natural resorbable polymers, and provide the basis for mechanically robust scaffolds in tissue regeneration. ${ }^{105,106}$

Several studies focused on also tailoring the biological features of $\mathrm{BC}$ for tissue regeneration. Saska et al. developed BC type I collagen hydrogels to be used for in vitro bone regeneration. ${ }^{107} \mathrm{~A}$ controlled amount of collagen incorporated into $\mathrm{BC}$ membranes improves the properties of the gel formulations, BC-COL composites showing a more flexible structure than $\mathrm{BC}$ membranes alone, thus, the material being easier to handle during surgical procedures. BCCOL formulations enable in vitro growth and proliferation of the osteoblastic phenotype, as shown by the high ALP activity levels after 17 days of cell culture, and therefore qualify as biomaterials for bone tissue regeneration applications. ${ }^{107}$

Research dealing with $\mathrm{BC}$ scaffolds underlines an issue related to the pore size of $\mathrm{BC}$, which may be too small for cell ingrowth, and indicates some solutions. In this respect, Gao et al. prepared novel porous $\mathrm{BC}$ hydrogels with controlled sizes and shapes through the emulsion freeze-drying technique. The prepared BC gels possess high surface area and sufficient porosity as to be successfully used as tissue engineering scaffolds, empowered by excellent cell compatibility, as demonstrated by the proliferation of fibrous synovium-derived mesenchymal stem cells (MSCs) on the surface and inside the BC hydrogel matrices. ${ }^{108}$

Due to the natural refined three-dimensional nanofibril networks that it creates, $\mathrm{BC}$ qualifies as a non-toxic wound dressing, which sustains cellular growth and tissue regeneration. ${ }^{109-113}$

One drawback in using BC in this specific area comes from its slow or difficult absorption in the human body, which can limit adhesion and proliferation. ${ }^{114}$ This can be solved and controlled by associating $\mathrm{BC}$ with other natural polymers and obtaining new composite products with enhanced features.

Barud et al. prepared non-genotoxic BC-silk fibroin (SF) porous scaffolds to be applied successfully and safely in tissue regeneration. ${ }^{115} \mathrm{It}$ was found that the pore sizes of a scaffold matrix affect the mechanism and the rate of cell adhesion, migration and proliferation, and influence directional growth of the tissue into the matrix. Furthermore, their prepared BC/SF:50\% scaffold led to improved biocompatibility and suitability to induce cell adhesion, in comparison with pure BC scaffolds. ${ }^{115}$ The BC-Si formulations exhibited a defined, interconnected porous network, the best outcome and stability being provided by a 50\% SF content, which shows a major increase in cell adhesion and higher rates of cellular viability, as compared to pure $\mathrm{BC}$. The genotoxicity test revealed that the material is non-genotoxic, indicating safety for medical applications, especially in tissue regeneration. ${ }^{16}$

Considering its good biocompatibility, biodegradability, excellent osteoconduction properties and the ability to form 3D porous network structures, bacterial cellulose (BC) offers certain advantages for bone tissue engineering. ${ }^{117}$ Hydroxyapatite (HA) is frequently added to cellulose based scaffolds for bone tissue 
generation mainly due to its capacity to promote calcium phosphate mineralization. ${ }^{118}$

For example, a BC-HA composite hydrogel was implanted to resolve some bone defects in rat tibiae, and, after 4 weeks, no inflammatory reaction was present and the sites of bone defects were completely filled by the new BC-HA bone tissue. Moreover, these slow reabsorbing hydrogels accelerated the new bone formation, with a $\mathrm{Ca} / \mathrm{P}$ molar rate similar to physiological bone. ${ }^{119}$

BC-HA hydrogels modified with $\beta$-tri-calcium phosphate have been also prepared in order to obtain scaffolds with improved structural and functional properties. The morphological and rheological investigations of non-mineralized and bio-mineralized scaffolds revealed porous BC based hydrogel matrices that qualify as implants for bone tissue engineering. ${ }^{120}$

In order to explore their potential in treating osteochondral defects, new BC-HA composite hydrogels containing glycosaminoglycans were developed and characterized. These scaffolds supported good attachment and proliferation of osteoblast, and allowed tissue ingrowth without any immunological reaction after subcutaneous implantation in rat knees. Therefore, $\mathrm{BC}$ can be modified to mimic different tissues, desirable progressive regeneration of cartilage tissue and of the subchondral bone being noticed as indicators of functional capability. ${ }^{121}$

A different, CMC-HA, hybrid hydrogel scaffold was reported to promote the production of extracellular mineralized matrix, and to enhance osteoblast cell proliferation and metabolic activity. ${ }^{122}$ In order to obtain successful bone integration and regeneration, bone-repairing scaffolds require to be functionalized synergistically based on biomimetics. A hybrid polymeric film composed of chitosan (CS), carboxymethyl cellulose (CMC) and nanohydroxyapatite (n-HA) was waved in a concentric way to generate an anisotropic spiral-cylindrical matrix, with compositional and structural characteristics mimicking natural bone, as shown in Figure 2. ${ }^{123,124}$

The data collected from in vivo osteogenesis evaluation showed that the spiral-cylindrical structure occupied a determinant part in bone regeneration. The newly formed bone tissue penetrated the entire matrix architecture and formed a medullary cavity in the epicentre of the spiral cylinder.
For the BC-CMC hydrogels, the presence of HA may influence the network features and might evolve an oxidative stress to the cells, which could in the end result in a major percentage of comets (cells with damaged DNA). ${ }^{125}$

\section{Cartilage regeneration}

Human articular cartilage displays aneural, avascular and also non-lymphatic characteristics, which make the repairing process quite difficult. The injuries of cartilage are normally followed by necrosis instead of an inflammatory response, and therefore innovative strategies are needed to repopulate and regenerate the cartilage defects. ${ }^{126}$

Currently, there are no clinical satisfactory solutions for cartilage tissue regeneration. ${ }^{127}$ The most widely used clinical strategy to heal cartilage trauma involves penetrating the wound to the subchondral bone, allowing the access of blood flow and new biological material. ${ }^{128}$ However, this type of clinical treatments often result in the formation of fibrocartilaginous tissue (Fig. 3), which is weaker than the original one, failing to integrate properly with surrounding tissue, and degrading over an interval between 6 to 12 months. ${ }^{129,142}$

During the last few years, material scientists and tissue engineers have tried to help clinicians by confronting the challenge of manufacturing porous 3D scaffolds, which resemble the chemical composition and architecture of the extracellular matrix (ECM) of cartilage. ${ }^{130-132}$ An optimal scaffold material chosen for articular cartilage engineering must support the growth and proliferation of chondrocytes or mesenchymal stem cells, facilitate their diffusion throughout the matrix, and have appropriate mechanical strength, stability and flexibility to mimic native articular cartilage. ${ }^{133,134}$

Injectable hydrogel-based scaffolds are the key players in the field since they can be delivered in a minimally invasive manner, providing biocompatibility, biodegradability, a highly porous 3D architecture and the perfect platform to efficiently encapsulate and deliver cells. ${ }^{135-137}$

Injectable hydrogels, based on CMC and a dialdehyde/gelatin/borate complex, are biocompatible, biodegradable and ECMmimicking scaffolds with great possibilities in repairing various cartilaginous defects. They show a porous network structure, with negligible inflammatory or immunological response, and integrate well within the cartilage defect area, stabilizing and preventing further degeneration, 
which is an essential aspect for osteoarthritis and chondrocytes-supported growth and proliferation within the matrix. ${ }^{138}$

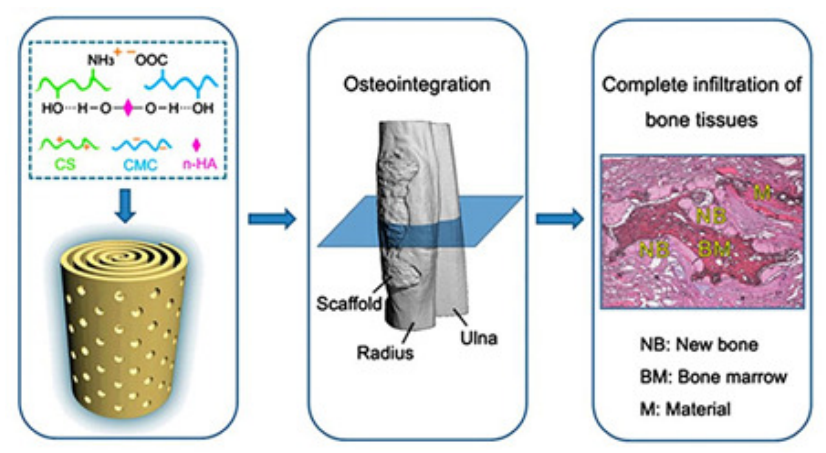

Figure 2: Biomimetic spiral-cylindrical scaffold based on hybrid chitosan/cellulose/nano-hydroxyapatite membrane (reprinted with permission from H. Yi et al., ${ }^{123}$ Copyright $\odot 2016$ Springer Nature Publishing and from H. Jiang et al., ${ }^{124}$ Copyright $\odot 2013$ ACS Publishing Group)
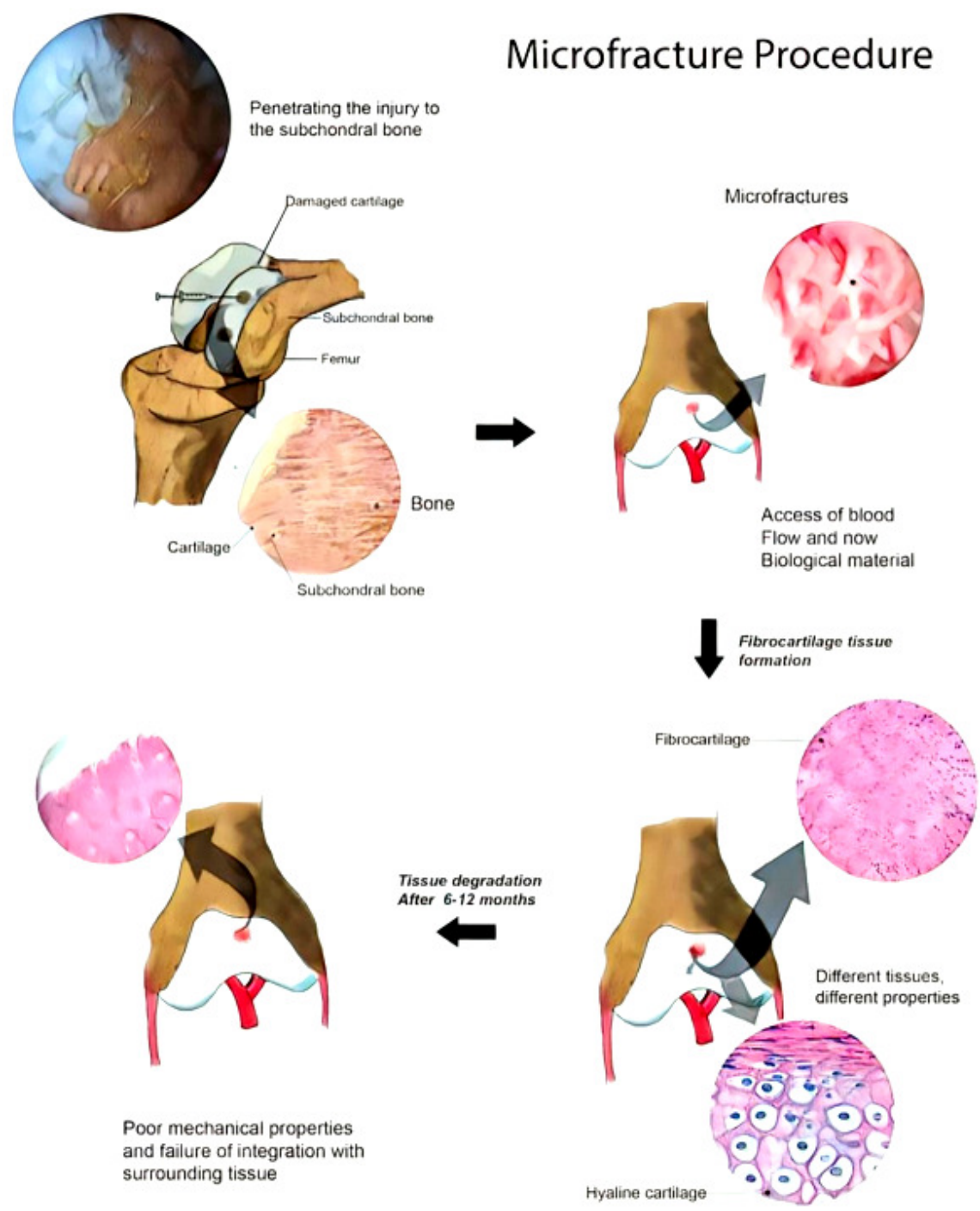

Poor mechanical properties and failure of integration with surrounding tissue

Figure 3: Common clinical procedure used to heal cartilage injury (reprinted with permission from D. A. SánchezTéllez et al., ${ }^{142}$ Copyright $@ 2017$, MDPI AG) 
Silated hydroxypropyl methylcellulose (SiHPMC) is a more complex cellulose derivative employed in the preparation of hydrogels designed to be used as scaffold materials for proliferation and differentiation of osteogenic cells in cartilage tissue engineering. ${ }^{139}$

Buchtová et al. developed an injectable hydrogel based on a silanized cellulose derivative: hydroxypropyl methylcellulose interlinked with silica fibers. ${ }^{140}$ They proved that the compressive modulus of the hydrogel could be tunable, depending on the covalent bonding between the biopolymer and silica fibres. In other approaches, the incorporation of bioactive species, such as cells, growth factors, peptides and proteins into the materials, is proposed to improve the properties of hydrogel scaffolds. ${ }^{141,142}$ A limitation of using $\mathrm{BC}$ hydrogels in tissue engineering lies in the reduced pore size of its scaffolds $(\sim 0.02-10$ $\mu \mathrm{m})$, smaller than the mammalian cell size, as a result, the dense network of the hydrogel cannot penetrate mammalian cells. The pore diameter can be increased with monodisperse agarose microparticles, resulting in an interconnected porous network, with pores ranging from 300 to $500 \mu \mathrm{m}$. Chondrocyte cells seeded on these scaffolds for 14 days were distributed uniformly on the surface of the matrix and attached within the pores, displaying higher viability, compared to unmodified BC substrates. ${ }^{143}$

Recently, 15\% BC content hydrogels have been reported to meet the mechanical requirements of auricular cartilage replacement. Avila et al. investigated the biocompatibility of $17 \% \mathrm{BC}$ hydrogels, observing its behaviour in vivo and in vitro, and concluded that $\mathrm{BC}$ gels, with an increased cellulose content, represent suitable non-resorbable scaffolds for auricular cartilage tissue engineering in terms of mechanical strength and low host tissue response. ${ }^{144}$

A physical cross-linked hydrogel based on polyvinyl alcohol (PVA) and BC has been also proposed for cartilage repair due to excellent physical and thermo-mechanical performance. BC largely improves the stability and reinforces the mechanical properties of the 3D network structure, promoting cell growth and proliferation within the matrix. ${ }^{145}$

\section{Miscellaneous tissue engineering applications}

$\mathrm{BC}$ hydrogels also appear to be a promising candidate for artificial blood vessels. In combination with PVA, composite hydrogels with improved mechanical properties and water permeability are obtained. This composite achieves some of the features of native blood vessels and can be considered a new biomaterial for vascular grafts. ${ }^{146}$

Artificial cornea research is another field that prefers soft hydrogel formulations based on cellulose derivatives for tissue regeneration, instead of formerly used rigid prostheses. ${ }^{147}$

Research is focused on designing and preparing a hydrogel matrix that mimics natural cornea and combines cell adhesion, proper permeability to nutrients and an overall satisfactory environment for rapid cell growth. ${ }^{148,149}$ The same combination between BC and PVA has great potential in keratoprosthetics. BC-PVA composite hydrogel matrices exhibit high water content, appropriate UV absorbance, high visible light transmittance and suitable mechanical behaviour and thermal resistance to qualify as hybrid cornea biomaterials. ${ }^{150}$

Redox-initiated modification of MC allows the preparation of a biocompatible material, which may serve as natural filler for soft tissue augmentation and reconstruction. The enzymatic treatment showed complete degradation of the hydrogel scaffolds after $48 \mathrm{~h}$ and co-culture experiments with human dermal fibroblasts evidenced the cytocompatibility of these materials. ${ }^{151}$

Thermo-sensitive hydrogels with high water retention capacity, mechanical properties that mimic those of living tissues and having the ability to experience reversible sol-gel transitions upon exposure to physiological temperature could serve as cell culture scaffolds for tissue regeneration. Because the transition temperature of $\mathrm{MC}\left(60-80{ }^{\circ} \mathrm{C}\right)$ is above physiological temperature, a series of modifications are necessary to permit MC to be utilized in different tissue engineering applications. ${ }^{152,153}$

Liu et al. grafted $\mathrm{MC}$ to poly (Nisopropylacrylamide) (PNIPAAm) to combine the thermo-sensitive characteristics of both materials. The resulting hydrogels are strongly temperature responsive and their lower critical solution temperature (LCST) can be easily modulated by adjusting the ratios of the two components. The mechanical properties of the copolymeric hydrogels were enhanced by the incorporation of PNIPAAm, thus increasing their potential as blood vessel barriers. ${ }^{154}$

Thermo-reversible polymers are also attractive scaffold candidates in traumatic injuries of the 
central nervous system, foremost due to the minimally invasive delivery process. Stabenfeldt et al. fabricated a bioactive scaffold for neural tissue engineering by using $\mathrm{MC}$, functionalized with laminin-1(LN). ${ }^{155}$ The tests on primary rat cortical neurons reported that the MC-LN hydrogels exhibited LCST at physiological temperature and promoted enhanced cell adhesion and viability, as compared to unmodified and oxidized MC, and therefore they may act as a delivery vehicle for neural cell transplantation procedures.

In another study, Tate et al. developed a MC hydrogel scaffold to be used in post-injury brain tissue engineering, by using MC solutions that turn into a soft gel at physiological temperature. After acellular 2\% MC was easily injected into the injured brains of rats for 1 week, it was evidenced that MC hydrogel scaffolds did not alter the injury cavity, and that the matrix can be employed to recondition brain defects. ${ }^{156}$

Cellulose-based hydrogels also found application in the greatly challenging field of nerve regeneration, in which the major hurdle is the limited regenerative capacity of this complex system. $^{46}$ BC can be used in the form of tracheotomy tubes for reconstructive surgery, such as blood vessels in the form of neurotubes for the regeneration of nerves. Earlier studies have found novel epithelial cell sheets to organize over these artificial BC tubes, demonstrating the triumphant application of $\mathrm{BC}$ in tissue implantation. $^{157}$

In addition, $\mathrm{Xu}$ et al. developed a cellulosepolyaniline (PANI) conductive hydrogel matrix in which the hydrophilic, more rigid, natural hydrogel serves as a template for the soft, hierarchical arrangement of PANI and does not interfere with its good electrical conductivity. On the basis of the fact that the pure cellulose hydrogel was an inert material for neural repair and PANI played an indispensable role in peripheral nerve regeneration, the established hierarchical micro-nano-structure could exceptionally induce the adhesion and guiding extension of neurons, revealing its great potential in the biomedical field. Finally, the composite material exhibited proper biocompatibility, good mechanical behaviour and an excellent sciatic nerve guidance conduit in rats. ${ }^{158}$

Several studies have shown that the tunable properties of natural polymer-based systems can be used to adjust the defects or to fulfil some of the harsh requirements of this research field. In many cases, the combination between natural and synthetic polymers allows the development of hydrogel matrices, which are able to mimic native neural tissues and support the regeneration of damaged nervous systems. ${ }^{159,160}$

\section{CONCLUSION}

Hydrogels based on cellulose and various cellulose derivatives provide biocompatible and biodegradable 3D frameworks with high water uptake, tuneable functionalities and versatile physico-chemical characteristics, in addition to the more general advantages of cellulose, such as being a highly abundant and inexpensive resource, as well as being prepared by costeffective methods.

This outstanding set of favourable properties offers almost endless possibilities of application and this mini-review is centred on some important elements concerning the design, features and use of cellulose-based hydrogels in the vast domain of tissue engineering. A myriad of formulations can be obtained by combining cellulose or cellulose derivatives with various molecules or polymers, which lead to the possibility to control their shape, size, porosity, surface morphology and functionality. The key factors that trigger the success of these hydrogels in preserving, restoring or enhancing tissue functions, in order to replace diseased or damaged tissues and organs, are their tailorable, highly swollen, porous architecture, their particular mechanical behaviour, the resemblance to soft tissues, the lack of an immune response and their ability to promote cell adhesion, growth and proliferation within the matrix, after a relatively facile delivery directly to the damaged area.

In light of this, cellulose-based hydrogels can function as effective extracellular matrices that direct cellular behaviour, regenerate damaged tissues and enable controlled degradability, which makes them excellent candidates for tissue engineering applications.

ACKNOWLEDGEMENTS: This work was supported by a grant of the Romanian Ministry of Research and Innovation, CCCDI - UEFISCDI, project number PN-III-P1-1.2-PCCDI-20170697/13PCCDI/2018, within PNCDI III.

\section{REFERENCES}

1 D. Howard, L. D. Buttery, K. M. Shakesheff and S. J. Roberts, J. Anat., 213, 66 (2008), https://doi.org/10.1111/j.1469-7580.2008.00878.x 
2 I. M. El-Sherbiny and M. H. Yacoub, Glob. Cardiol. Sci. Pract., 3, $316 \quad$ (2013), https://doi.org/10.5339/gcsp.2013.38

3 O. Wichterle and D. Lim, Nature, 185, 117 (1960), https://doi.org/10.1038/185117a0

4 J. Byeongmoon, W. K. Sung and Y. H. Bae, $A d v$. Drug Deliv. Rev., 54, $51 \quad$ (2002), https://doi.org/10.1016/S0169-409X(01)00242-3

5 T. R. Hoare and D. S. Kohane, Polymer, 49, 1993 (2008), https://doi.org/10.1016/j.polymer.2008.01.027

6 E. M. Ahmed, J. Adv. Res., 6, 105 (2015), https://doi.org/10.1016/j.jare.2013.07.006

7 D. Ciolacu, C. Rudaz, M. Vasilescu and T. Budtova, Carbohyd. Polym., 151, 392 (2016), https://doi.org/10.1016/B978-0-444-63774-1.00011-9

8 Y. Zhang, H. F. Chan and K. W. Leong, Adv. Drug Deliv. Rev., $\quad$ 65, $104 \quad$ (2013), https://doi.org/10.1016/j.addr.2012.10.003

9 L. Rizzello, R. Cingolani and P. P. Pompa, Nanomedicine, $\quad \mathbf{8}, 807 \quad$ (2013), https://doi.org/10.2217/nnm.13.63

10 D. Bastani, N. Esmaeili and M. Asadollahi, J. Ind. Eng. Chem., 19, 375 (2013), https://doi.org/10.1016/j.jiec.2012.09.019

11 S. Kango, S. Kalia, A. Celli, J. Njuguna, Y. Habibi et al., Progr. Polym. Sci., 38, 1232 (2013), https://doi.org/10.1016/j.progpolymsci.2013.02.003

12 L. Sartore, G. Vox and E. Schettini, J. Polym. Environ., $\quad$ 21, 718 (2013), https://doi.org/10.1007/s10924-013-0574-2

13 L. Li, F. Yu, L. Zheng, R. Wang, W. Yan et al., J. Orthop. Translat., 17, $26 \quad$ (2019), https://doi.org/10.1016/j.jot.2018.09.003

14 B. Cullen, P. W. Watt, C. Lundqvist, D. Silcock, R. J. Schmidt et al., Int. J. Biochem. Cell. Biol., 34, 1544 (2002), https://doi.org/10.1016/S1357-2725(02)000547

15 D. Ciolacu, in "Cellulose-Based Superabsorbent Hydrogels", edited by Md. I. H. Mondal, Springer International Publishing AG, 2019, pp. 65-95, https://doi.org/10.1007/978-3-319-77830-3_6

16 B. Dhandayuthapani, Y. Yoshida, T. Maekawa and D. Sakthi Kumar, Int. J. Polym. Sci., 2011, 1687 (2011), https://doi.org/10.1155/2011/290602

17 R. Kumar, M. Griffin and P. E. Butler, Open Orthop. J., 10, $862 \quad$ (2016), https://doi.org/10.2174/1874325001610010862

18 S. A. Sell, P. S. Wolfe, K. Garg, J. M. McCool, I. A. Rodriguez et al., Polymers, 2, 522 (2010), https://doi.org/10.3390/polym2040522

19 E. Piskin, J. Biomater. Sci. Polym. Ed., 6, 775 (1994), https://doi.org/10.1163/156856295X00175

20 Y. Ji, K. Ghosh, X. Z. Shu, B. Li, J. C. Sokolov et al., Biomaterials, 27, $3782 \quad$ (2006), https://doi.org/10.1016/j.biomaterials.2006.02.037

21 S. Stratton, N. B. Shelke, K. Hoshino, S. Rudraiah and S. G. Kumbar, Bioact. Mater., 1, 93 (2016), https://doi.org/10.1016/j.bioactmat.2016.11.001
22 A. Uliniuc, M. Popa, T. Hamaide and M. Dobromir, Cellulose Chem. Technol., 46, 1 (2012), http://www.cellulosechemtechnol.ro/pdf/CCT12(2012)/p.1-11.pdf

23 J. Zhu and R. E. Marchant, Expert. Rev. Med. Devices, $\quad$ 8, $607 \quad$ (2011), https://doi.org/10.1586/erd.11.27

24 J. A. Hubbell, Curr. Opin. Biotechnol., 10, 123 (1999), https://doi.org/10.1016/S0958-1669(99)800214

25 K. Y. Lee and D. J. Mooney, Chem. Rev., 101, 1869 (2001), https://doi.org/10.1021/cr000108x

26 D. F. Williams, in "The Williams Dictionary of Biomaterials", edited by D. F. Williams, Liverpool University Press, 1999, pp. 220-226, https://doi.org/10.5949/UPO9781846314438.018

27 C. A. Léon and Y. Léon, Adv. Colloid. Interface Sci., 76, 341 (1998), https://doi.org/10.1016/S00018686(98)00052-9

28 R. Langer and J. P. Vacanti, Tissue Eng. Sci., 260, 920 (1993), https://doi.org/10.1126/science.8493529

29 U. A. Stock and J. P. Vacanti, Ann. Rev. Med., 52, 443 https://doi.org/10.1146/annurev.med.52.1.443

${ }_{30}$ S. Yang, K. F. Leong, Z. Du and C. K. Chua, Tissue Eng., 7, $679 \quad$ (2001), https://doi.org/10.1089/107632701753337645

31 K. Y. Lee and D. J. Mooney, Chem. Rev., 101, 1869 (2001), https://doi.org/10.1021/cr000108x

32 M. P. Lutolf and J. A. Hubbell, Nat. Biotechnol., 23, 47 (2005), https://doi.org/10.1038/nbt1055

33 B. V. Slaughter, S. S. Khurshid, O. Z. Fisher, A. Khademhosseini and N. A. Peppas, Adv. Mater., 21, 3307 (2009), https://doi.org/10.1002/adma.200802106

34 K. Markstedt, A. Mantas, I. Tournier, H. M. Avila, D. Hagg et al., Biomacromolecules, 16, 1489 (2015), https://doi.org/10.1021/acs.biomac.5b00188

35 D. Ciolacu, F. Ciolacu and V. I. Popa, Cellulose Chem. Technol., 45, $13 \quad$ (2011), http://www.cellulosechemtechnol.ro/pdf/CCT12(2011)/p.13-21.pdf

36 Y. Liu, L. Li, G. Dong, Y. Yang, C. Zheng et al., Cellulose Chem. Technol., 50, 897 (2016), http://www.cellulosechemtechnol.ro/pdf/CCT910(2016)/p.897-903.pdf

37 C. M. Agrawal, J. L. Ong, M. R. Appleford and G. Mani, in "Introduction to Biomaterials - Basic Theory with Engineering Applications", edited by W. M. Saltzman, S. Chien, Cambrigde University Press, 2014, pp.

198-232, https://doi.org/10.1017/CBO9781139035545

38 J. Mao, L. Shuhui, J. Huang, K. Meng, G. Chen et $a l$., in "Cellulose-Based Superabsorbent Hydrogels", edited by Md. I. H. Mondal, Springer International $\begin{array}{llll}\text { Publishing } & \text { AG, 2019, } & \text { pp. }\end{array}$ https://doi.org/10.1007/978-3-319-77830-3_5

39 J. C. Courtenay, R. I. Sharma and J. L. Scott, Molecules, 23, 654 (2018), https://doi.org/10.3390/molecules23030654 
40 D. Ciolacu, A. M. Oprea, N. Anghel, G. Cazacu and M. Cazacu, Mater. Sci. Eng. C, 32, 452 (2012), https://doi.org/10.1016/j.msec.2011.11.018

${ }^{41}$ L. H. Fu, C. Qi, M. G. Ma and P. Wan, J. Mater. $\begin{array}{lllll}\text { Chem. } & B, & \mathbf{7}, & 1541 & \text { (2019), }\end{array}$ https://doi.org/10.1039/C8TB02331J

${ }^{42}$ Y. Budama-Kilinc, R. Cakir-Koc, B. Aslan, B. Özkan, H. Mutlu et al., in "Biomaterials in Regenerative Medicine", edited by L. Dobrzansk, Intech, 2018, pp. 277-301, https://doi.org/10.5772/intechopen.70409

43 J. L. Drury and D. J. Mooney, Biomaterials, 24, $4337 \quad$ (2003), https://doi.org/10.1016/s01429612(03)00340-5

44 J. E. Babensee, J. M. Anderson, L. V. McIntire and A. G. Mikos, Adv. Drug Deliv. Rev., 33, 111 (1998), https://doi.org/10.1016/S0169-409X(98)00023-4

45 B. Ř́hová, Adv. Drug Deliv. Rev., 42, 65 (2000), https://doi.org/10.1016/S0169-409X(00)00054-5

46 L. Dobrzański, Arch. Mater. Sci. Eng., 69, 53 (2014),

http://www.amse.acmsse.h2.pl/vol69_2/6921.pdf

47 J. A. Hubbell, Curr. Opin. Biotechnol., 10, 123 (1999), https://doi.org/10.1016/S0958-1669(99)800214

48 L. G. Griffith and G. Naughton, Science, 295, 1009 (2002), https://doi.org/10.1126/science.1069210

49 D. M. Suflet, I. Popescu and I. M. Pelin, Cellulose Chem. Technol., 51, 23 (2017), http://www.cellulosechemtechnol.ro/pdf/CCT12(2017)/p.23-34.pdf

50 J. L. Drury and D. J. Mooney, Biomaterials, 24, $4337 \quad$ (2003), https://doi.org/10.1016/s01429612(03)00340-5

51 C. Chang and L. Zhang, Carbohyd. Polym., 84, 40 (2011), https://doi.org/10.1016/j.carbpol.2010.12.023

52 O. Baniukaitiene, A. Palaveniene, N. Babenko, V. Harkavenko, V. Kharchenko et al., Cellulose Chem. Technol., $\quad 52, \quad 441 \quad$ (2018), http://www.cellulosechemtechnol.ro/pdf/CCT56(2018)/p.441-448.pdf

53 S. M. Fijul Kabir, P. P. Sikdar, B. Haque, M. A. Rahman Bhuiyan and A. Ali, Prog. Biomater., 7, 153 (2018), https://doi.org/10.1007/s40204-018-0095-0

54 G. F. Muschler, C. Nakamoto and L. G. Griffith, J. Bone Joint Surg., 86, $1541 \quad$ (2004), https://doi.org/10.2106/00004623-200407000-00029

55 D. N. S. Hon, in "Polysaccharides in Medical Applications", edited by S. Dumitriu, Marcel Dekker Inc., New York, 1996, pp. 87-105.

56 S. J. Eichhorn, C. A. Baillie, N. Zafeiropoulos, L. Y. Mwaikambo, M. P. Ansell et al., J. Mater. Sci., 36, 2107

https://doi.org/10.1023/A:1017512029696

(2001),

57 R. Salihu, C. Y. Foong, A. I. A. Razak, M. R. A. Kadir, A. H. M. Yusof et al., Cellulose Chem. Technol., $\quad \mathbf{5 3}, \quad 1 \quad$ (2019), http://www.cellulosechemtechnol.ro/pdf/CCT12(2019)/p.1-13.pdf
58 R. Jonas and L. F. Farah, Polym. Degrad. Stabil., 59, 101 (1998), https://doi.org/10.1016/S01413910(97)00197-3

59 S. D. Dutta, D. K. Patell and K. T. Lim, J. Biol. Eng., 13, 55 (2019), https://doi.org/10.1186/s13036019-0177-0

60 B. V. Mohite, S. H. Koli and S. V. Patil, in "Cellulose-based Superabsorbent Hydrogels", edited by I. H. Mondal, Springer Nature, 2018, pp. 1-22, https://doi.org/10.1007/978-3-319-77830-3_2

61 A. Okiyama, M. Motoki and S. Yamanaka, Food Hydrocoll., $\quad$ 6, $503 \quad$ (1993), https://doi.org/10.1016/S0268-005X(09)80074-X

62 S. Van Vlierberghe, P. Dubruel and E. Schacht, Biomacromolecules, 12, $1387 \quad$ (2011), https://doi.org/10.1021/bm200083n

${ }_{63}$ J. E. Rodriguez-Chanfrau, M. L. Dos Santos, C. Dos Santos Riccardi, G. M. De Olyveira, M. Hernández-Escalona et al., Cellulose Chem. Technol., 51, 673 (2017), http://www.cellulosechemtechnol.ro/pdf/CCT7-

8(2017)/p.673-680.pdf

64 D. W. Hutmacher, Biomaterials, 21, 2529 (2000), https://doi.org/10.1016/B978-008045154-1.50021-6

65 C. J. Grande, F. G. Torres, C. M. Gomez and M. C. Bano, Acta Biomater., 5, 1605 (2009), https://doi.org/10.1016/j.actbio.2009.01.022

66 S. Saska, H. S. Barud, A. M. M. Gaspar, R. Marchetto, S. J. L. Ribeiro et al., Int. J. Biomater., 2011, 1 (2011), https://doi.org/10.1155/2011/175362

67 M. Ul-Islam, T. Khan and J. K. Park, Carbohyd.

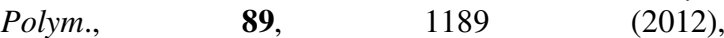
https://doi.org/10.1016/j.carbpol.2012.03.093

68 A. Sannino, C. Demitri and M. Madaghiele, $\begin{array}{llll}\text { Materials, } & \text { 2, } & 353 & \text { (2009), }\end{array}$ https://doi.org/10.3390/ma2020353

69 M. C. Tate, D. A. Shear, S. W. Hoffman, D. G. Stein and M. C. LaPlaca, Biomaterials, 22, 1113 (2001), https://doi.org/10.1016/S0142-9612(00)003483

70 K. Te Nijenhuis, Polym. Bull., 58, 27 (2007), https://doi.org/10.1007/s00289-006-0610-7

71 N. Sarkar, J. Appl. Polym. Sci., 24, 1073 (1979), https://doi.org/10.1002/app.1979.070240420

72 A. K. Bajpai, S. K. Shukla, S. Bhanu and S. Kankane, Prog. Polym. Sci., 33, 1088 (2008), https://doi.org/10.1016/j.progpolymsci.2008.07.005

73 M. Yamato, M. Utsumi, A. Kushida, C. Konno, A. Kikuchi et al., Tissue Eng., 7, 473 (2001), https://doi.org/10.1089/10763270152436517

74 M. P. Lutolf, J. L. Lauer-Fields, H. G. Schmoekel, A. T. Metters, F. E. Weber et al., Proc. Natl. Acad. Sci. U. S. A., 100, $5413 \quad$ (2003), https://doi.org/10.1073/pnas.0737381100

75 T. Shimizu, H. Sekine, J. Yang, Y. Isoi, M. Yamato et al., Faseb. J., 20, 708 (2006), https://doi.org/10.1096/fj.05-4715fje 
76 Y. Hayashida, K. Nishida, M. Yamato, J. Yang, H. Sugiyama et al., Invest. Ophthalmol. Vis. Sci., 47, 552 (2006), https://doi.org/10.1167/iovs.05-0995

77 Y. Akiyama, A. Kushida, M. Yamato, A. Kikuchi and T. Okano, J. Nanosci. Nanotechnol., 7, 796 (2007), https://doi.org/10.1166/jnn.2007.509

78 N. Matsuda, T. Shimizu, M. Yamato and T. Okano, Adv. Mater., 19, $3089 \quad$ (2007), https://doi.org/10.1002/adma.200701978

${ }^{79}$ C. H. Chen, C. C. Tsai, W. Chen, F. L. Mi, H. F. Liang et al., Biomacromolecules, 7, 736 (2006), https://doi.org/10.1021/bm0506400

${ }^{80}$ S. Thirumala, J. M. Gimble and R. V. Devireddy, Cells, $\quad 3, \quad 460 \quad$ (2013), https://doi.org/10.3390/cells2030460

81 Y. F. Tang, X. Y. Wang, Y. Li, M. Lei, Y. Dua et al., Carbohyd. Polym., 82, 833 (2010), https://doi.org/10.1016/j.carbpol.2010.06.003

82 A. R. Amini, C. T. Laurencin and S. P. Nukavarapu, Crit. Rev. Biomed. Eng., 40, 363 (2012), https://doi.org/10.1615/CritRevBiomedEng.v40.i5.10

83 R. J. O' Keefe and J. Mao, Tissue Eng. Part B Rev., 17, 389

(2011),

https://doi.org/10.1089/ten.teb.2011.0475

${ }_{84}$ M. A. Fernandez-Yague, S. A. Abbah, L. McNamara, D. I. Zeugolis, A. Pandit et al., Adv. Drug Deliv. $\quad$ Rev., $\quad \mathbf{8 4 ,} \quad 1 \quad$ (2015), https://doi.org/10.1016/j.addr.2014.09.005

85 M. M. Stevens, Mater. Today, 11, 18 (2008), https://doi.org/10.1016/S1369-7021(08)70086-5

86 J. E. Samorezov and E. Alsberg, Adv. Drug Deliv. Rev., $\quad 84, \quad 45 \quad$ (2015), https://doi.org/10.1016/j.addr.2014.11.018

87 K. Y. Lee and D. J. Mooney, Chem. Rev., 101, 1869 (2001), https://doi.org/10.1021/cr000108x

${ }^{88}$ B. V. Slaughter, S. S. Khurshid, O. Z. Fisher, A. Khadem-Hosseini and N. A. Peppas, Adv. Mater., 21, 3307 (2009), https://doi.org/10.1002/adma.200802106

89 M. Kaliva, M. Chatzinikolaidou and M. Vamvakaki, in "Smart Materials for Tissue Engineering”, edited by Q. Wang, Royal Society of Chemistry, UK, 2017, pp. 1-38, https://doi.org/10.1039/9781788010542-00001

90 J. C. Fricaina, P. L. Granjac, M. A. Barbosa, B. de Jéso, N. Barthe et al., Biomaterials, 23, 971 (2002), https://doi.org/10.1016/S0142-9612(01)00152-1

91 E. Ekholm, M. Tommila, A. P. Forsback, M. Märtson, J. Holmbom et al., Acta Biomater., 1, 535 (2005), https://doi.org/10.1016/j.actbio.2005.05.003

92 M. Sukul, Y. Min, S. Lee and B. Lee, Eur. Polym. J., 73, $308 \quad$ (2015), https://doi.org/10.1016/j.eurpolymj.2015.10.022

93 O. Gauthier, J. M. Bouler, P. Weiss, J. Bosco, E. Aguado et al., Bone, 25, 71 (1999), https://doi.org/10.1016/S8756-3282(99)00137-4

94 O. Gauthier, R. Muller, D. von Stechow, B. Lamy, P. Weiss et al., Biomaterials, 26, 5444 (2005), https://doi.org/10.1016/j.biomaterials.2005.01.072
95 X. Bourges, P. Weiss, G. Daculsi and G. Legeay, Adv. Colloid. Interface Sci., 2, 215 (2002), https://doi.org/10.1016/S0001-8686(02)00035-0

96 X. Bourges, P. Weiss, A. Coudreuse and G. Daculsi, Biopolymers, 63, $232 \quad$ (2002), https://doi.org/10.1002/bip.10053

97 B. H. Fellah, P. Weiss, O. Gauthier, T. Rouillon, P. Pilet et al., J. Orthop. Res., 24, 628 (2006), https://doi.org/10.1002/jor.20125

98 L. Trombelli and R. Farina, J. Clin. Periodontol., 35, 117 (2008), https://doi.org/10.1111/j.1600051X.2008.01265.x

99 A. Sculean, D. Nikolidakis and F. Schwarz, J. Clin. Periodontol., $\quad 35, \quad 106 \quad$ (2008), https://doi.org/10.1111/j.1600-051X.2008.01263.x

${ }^{100}$ X. Struillou, H. Boutigny, Z. Badran, B. H. Fellah, O. Gauthier et al., J. Mater. Sci. Mater. Med., 22, 1707 (2011), https://doi.org/10.1007/s10856-011-4344-1

${ }^{101}$ D. Boix, P. Weiss, O. Gauthier, J. Guicheux, J. M. Bouler et al., J. Mater. Sci. Mater. Med., 17, 1145 (2006), https://doi.org/10.1007/s 10856-006-0542-7

102 P. Weiss, P. Layrolle, L. P. Clergeau, B. Enckel, P. Pilet et al., Biomaterials, 28, 3295 (2007), https://doi.org/10.1016/j.biomaterials.2007.04.006

${ }^{103}$ X. Struillou, A. Fruchet, M. Rakic, Z. Badran, G. Rethore et al., Dent. Mater. J., 37, 825 (2018), https://doi.org/10.4012/dmj.2017-238

104 A. Nakayama, A. Kakugo, J. P. Gong, Y. Osada, M. Takai et al., Adv. Funct. Mater., 14, 1124 (2004), https://doi.org/10.1002/adfm.200305197

${ }^{105}$ D. Klemm, B. Heublein, H. P. Fink and A. Bohn, Angew. Chem., Int. Ed., 44, 3358 (2005), https://doi.org/10.1002/anie.200460587

${ }^{106}$ C. Zhijiang and Y. Guang, J. Appl. Polym. Sci., 120, 2938 (2011), https://doi.org/10.1002/app.33318

107 S. Saska, L. N. Teixeira, P. T. de Oliveira, A. M. M. Gaspar, S. J. L. Ribeiro et al., J. Mater. Chem., 22, 22102 (2012), https://doi.org/10.1039/C2JM33762B

108 C. Gao, C. Yang, Y. Wan and K. Dai, J. Porous Mat., 18, 139 (2019), https://doi.org/10.1007/s10934010-9364-6

${ }^{109}$ G. Helenius, H. Bäckdahl, A. Bodin, U. Nannmark, P. Gatenholm et al., J. Biomed. Mater. Res. A., 76, 431 (2006), https://doi.org/10.1002/jbm.a.30570

110 A. Svensson, E. Nicklasson, T. Harrah, B. Panilaitis, D. L. Kaplan et al., Biomaterials, 26, 419 (2005),

https://doi.org/10.1016/j.biomaterials.2004.02.049

111 R. Portela, C. R. Leal, P. L. Almeida and R. G. Sobral, Microb. Biotechnol., 12, 586 (2019), https://doi.org/10.1111/1751-7915.13392

${ }^{112}$ J. D. Fontana, A. M. de Souza, C. K. Fontana, I. L. Torriani, J. C. Moreschi et al., Appl. Biochem. Biotechnol., 24, 253 (1990), https://doi.org/10.1007/BF02920250

113 D. Klemm, D. Schumann, U. Udhardt and S. Marsch, Prog. Polym. Sci., 26, 1561 (2001), https://doi.org/10.1016/S0079-6700(01)00021-1 
114 N. Alexandre, I. Amorim, F. K. Andrade and F. Gärtner, J. Bioact. Compat. Polym., 28, 97 (2012), https://doi.org/10.1177/0883911512467643

${ }^{115}$ P. Wang, Y. Y. Jia, Y. Shi and J. T. Zheng, $A d v$. Mater. $\quad$ Res., $\quad 79, \quad 147 \quad$ (2009), https://doi.org/10.4028/www.scientific.net/AMR.7982.147

${ }^{116}$ H. G. de Oliveira Barud, R. R. da Silva, H. da Silva Barud, A. Tercjak, J. Gutierrez et al., Carbohyd. Polym., $\quad$ 128, $41 \quad$ (2015), https://doi.org/10.1016/j.carbpol.2015.04.007

117 T. R. Stumpf, X. Yang, J. Zhang and X. Cao, Mater. Sci. Eng. C, 82, 372 (2016), https://doi.org/10.1016/j.msec.2016.11.121

118 S. Saska, H. S. Barud, A. M. M. Gaspar, R. Marchetto, S. J. L. Ribeiro et al., Int. J. Biomater., 2011, 175362 https://doi.org/10.1155/2011/175362

119 J. C. Courtenay, R. I. Sharma and J. L. Scott, Molecules, 23, $\quad 654 \quad$ (2018), https://doi.org/10.3390/molecules23030654

${ }^{120}$ P. Basu, N. Saha, S. Bandyopadhyay and P. Saha, AIP Conf. Proc., 1843, 050008 (2017), https://doi.org/10.1063/1.4983000

${ }_{121}$ J. V. Kumbhar, S. H. Jadhav, D. S. Bodas, A. Barhanpurkar-Naik, M. R. Wani et al., Int. J. Nanomed., 12, 6437 (2017), https://doi.org/10.2147/IJN.S137361

${ }^{122}$ D. Pasqui, P. Torricelli, M. de Cagna, M. Fini and R. Barbucci, J. Biomed. Mater. Res. A, 102, 1568 (2013), https://doi.org/10.1002/jbm.a.34810

${ }^{123}$ H. Yi, F. U. Rehman, C. Zhao, B. Liu and N. He, Bone Res., 4, $16050 \quad$ (2016), https://doi.org/10.1038/boneres.2016.50

${ }^{124}$ H. Jiang, Y. Zuo, Q. Zou, H. Wang, J. Du et al., ACS Appl. Mater. Interfaces, 5, 12036 (2013), https://doi.org/10.1021/am4038432

${ }^{125}$ P. Basu, N. Saha, R. Alexandrova, B. AndonovaLilova, M. Georgieva et al., Int. J. Mol. Sci., 19, 3980 (2018), https://doi.org/10.3390/ijms 19123980

${ }^{126}$ M. W. Kessler and D. A. Grande, Organogenesis, 4, 28 (2008), https://doi.org/10.4161/org.6116

${ }^{127}$ P. Verdonk, A. Dhollander, K. F. Almqvist, R. Verdonk and J. Victor, Bone Jt. J., 97B, 318 (2015), https://doi.org/10.1302/0301-620X.97B3.34555

128 J. M. Case and J. M. Scopp, Sports Med. Arthrosc., 24 63 https://doi.org/10.1097/JSA.0000000000000113

${ }^{129}$ A. Siclari, G. Mascaro, C. Gentili, C. Kaps, R. Cancedda et al., Knee Surg. Sports Traumatol. Arthrosc., $\quad$ 22, $\quad 1225 \quad$ (2014), https://doi.org/10.1007/s00167-013-2484-1

${ }^{130}$ A. J. Sutherland, E. C. Beck, S. C. Dennis, G. L. Converse, R. A. Hopkins et al., PLoS ONE, 10, e0121966

https://doi.org/10.1371/journal.pone.0121966

${ }^{131}$ M. Sancho-Tello, F. Forriol, P. Gastaldi, A. RuizSaurí, J. J. Martín de Llano et al., Int. J. Artif. Organs, 38, 210 (2015), https://doi.org/10.5301/ijao.5000404
132 J. Wang, Q. Yang, N. Cheng, X. Tao, Z. Zhang et al., Mater. Sci. Eng. C, 61, 705 (2016), https://doi.org/10.1016/j.msec.2015.12.097

${ }^{133}$ C. Vinatier, O. Gauthier, A. Fatimi, C. Merceron, M. Masson et al., Biotechnol. Bioeng., 102, 1259 (2009), https://doi.org/10.1002/bit.22137

${ }^{134}$ S. Park, E. Lih, K. Park, Y. K. Joung and D. K. Han, Prog. Polym. Sci., 68, 77 (2017), https://doi.org/10.1016/j.progpolymsci.2016.12.003

${ }^{135}$ Y. Li, J. Rodrigues and H. Tomas, Chem. Soc. Rev., 41, 2193 (2012), https://doi.org/10.1039/C1CS15203C

${ }^{136}$ F. Chen, S. Yu, B. Liu, Y. Ni, C. Yu et al., Sci. Rep., 6, $20014 \quad$ (2016), https://doi.org/10.1038/srep20014

${ }^{137}$ X. Wang, X. Sun, G. Jiang, R. Wang, R. Hu et al., J. Appl. Polym. Sci., 128, 3289 (2013), https://doi.org/10.1002/app.38497

${ }^{138}$ B. Balakrishnan, N. Joshi and R. Banerjee, J. Mater. Chem. B, 1, $5564 \quad$ (2013), https://doi.org/10.1039/c3tb21056a

${ }^{139}$ C. Trojani, P. Weiss, J. F. Michiels, C. Vinatier, J. Guicheux et al., Biomaterials, 26, 5509 (2005), https://doi.org/10.1016/j.biomaterials.2005.02.001

${ }^{140}$ N. Buchtová, G. Réthoré, C. Boyer, J. Guicheux, F. Rambaud et al., J. Mater. Sci. Mater. Med., 24, 1875 (2013), https://doi.org/10.1007/s10856-013-4951-0

${ }^{141}$ T. Wang, J. H. Lai and F. Yang, Tissue Eng. Part A, 22, 1348 (2016), https://doi.org/10.1089/ten.TEA.2016.0306

${ }^{142}$ D. A. Sánchez-Téllez, L. Téllez-Jurado and L. M. Rodríguez-Lorenzo, Polymers, 9, 671 (2017), https://doi.org/10.3390/polym9120671

${ }^{143}$ N. Yin, M. D. Stilwell, T. M. Santos, H. Wang and D. B. Weibel, Acta Biomater., 12, 129 (2015), https://doi.org/10.1016/j.actbio.2014.10.019

${ }^{144}$ H. M. Ávila, S. Schwarz, E. M. Feldmann, A. Mantas, A. von Bomhard et al., Appl. Microbiol. Biotechnol., 98, $\quad 7423 \quad$ (2014), https://doi.org/10.1007/s00253-014-5819-z

${ }^{145}$ C. Castro, R. Zuluaga, O. J. Rojas, I. Filpponen, H. Orelma et al., RSC Adv., 5, 90742 (2015), https://doi.org/10.1039/C5RA16966F

${ }^{146}$ J. Tang, L. Bao, X. Li and F. F. Hong, J. Mater. Chem. B, 3, $8537 \quad$ (2015), https://doi.org/10.1039/C5TB01144B

${ }_{147}$ D. J. Carlsson, F. Li, S. Shimmura and M. Griffith, Curr. Opin. Ophthalmol., 14, 192 (2003), https://doi.org/10.1097/00055735-200308000-00004

${ }_{148}$ B. E. McCarey and F. R. Schmidt, Curr. Eye Res., 9, $1025 \quad$ (1990), https://doi.org/10.3109/02713689008997577

${ }^{149}$ R. A. Thoft, J. Friend and C. H. Dohlman, Arch. Ophthalmol., $\quad \mathbf{8 6}, \quad 685 \quad$ (1971), https://doi.org/10.1001/archopht.1971.0100001068701 3 ${ }^{150}$ J. Wang, C. Gao, Y. Zhang and Y. Wan, Mater. Sci. Eng. C, 30, $214 \quad$ (2010), https://doi.org/10.1016/j.msec.2009.10.006 
151 G. T. Gold, D. M. Varma, D. Harbottle, M. S. Gupta, S. S. Stalling et al., J. Biomed. Mater. Res. A, 102, 4536 (2014), https://doi.org/10.1002/jbm.a.35132 ${ }^{152}$ L. Li, H. Shan, C. Y. Yue, Y. C. Lam, K. C. Tam et al., Langmuir, 18, $7291 \quad$ (2002), https://doi.org/10.1021/la020029b

${ }^{153}$ M. Takahashi, M. Shimazaki and J. Yamamoto, J. Polym. Sci. Pol. Phys., 39, 91 (2001), https://doi.org/10.1002/1099-

0488(20010101)39:1<91::AID-POLB80>3.0.CO;2-C

${ }^{154}$ W. Liu, B. Zhang, W. W. Lu, X. Li, D. Zhu et al., Biomaterials, 25, $3005 \quad$ (2004), https://doi.org/10.1016/j.biomaterials.2003.09.077

155 S. E. Stabenfeldt, A. J. Garcia and M. C. LaPlaca, J. Biomed. Mater. Res. A, 77, 718 (2006), https://doi.org/10.1002/jbm.a.30638

${ }^{156}$ M. C. Tate, D. A. Shear, S. W. Hoffman, D. G. Stein and M. C. LaPlaca, Biomaterials, 22, 1113
(2001), https://doi.org/10.1016/s0142-9612(00)003483

${ }^{157}$ A. Baptista, I. Ferreira and J. Borges, in "Cellulose: Medical, Pharmaceutical and Electronic Applications", edited by T. G. M. Van De Ven, IntechOpen Limited, 2013, pp. 67-82, https://doi.org/10.5772/56721

158 D. Xu, L. Fan, L. Gao, Y. Xiong, Y. Wang et al., ACS Appl. Mater. Interfaces, 8, 17090 (2016), https://doi.org/10.1021/acsami.6b03555

159 V. S. Kulkarni, K. D. Butte and S. S. Rathod, Int. J. Pharm. Biol. Sci., 3, $1597 \quad$ (2012), https://www.researchgate.net/publication/236217541_ Natural_Polymers-_A_comprehensive_Review

${ }^{160}$ N. N. Madigan, S. McMahon, T. O’Brien, M. J. Yaszemski and A. J. Windebank, Respir. Physiol. Neurobiol., $\quad \mathbf{1 6 9}, \quad 183 \quad$ (2009), https://doi.org/10.1016/j.resp.2009.08.015 